\title{
NILAI-NILAI PENDIDIKAN KARAKTER DALAM DRAMATARI ARJA BASUR DI DESA ADAT TEGAL, DARMASABA BADUNG BALI
}

\author{
I Wayan Adi Gunarta \\ Program Studi Tari, Fakultas Seni Pertunjukan, Institut Seni Indonesia Denpasar \\ E-mail: adie_gunarta@yahoo.com
}

\begin{abstract}
Abstrak
Kesenian ialah hasil daya cipta, rasa, dan karsa manusia yang memiliki nilai-nilai falsafah kehidupan. Dramatari Arja Basur di Desa Adat Tegal, Darmasaba Badung Bali merupakan salah satu kesenian langka yang muncul sekitar tahun 1931 dan dalam pertunjukannya, selain menyajikan nilai estetika juga memuat nilai-nilai pendidikan. Nilai-nilai itu terkandung dalam cerita, yakni melalui tokoh protagonis dan tokoh antagonis. Tujuan penelitian ini adalah untuk mengkaji fungsi dan nilai-nilai pendidikan karakter yang terkandung dalam dramatari Arja Basur. Metode penelitian yang digunakan adalah penelitian kualitatif dengan teknik pengumpulan data melalui wawancara, observasi, studi kepustakaan, dan dokumentasi. Hasil penelitian menunjukkan bahwa dramatari Arja Basur memuat konsepsi rwa bhineda, yakni dualitas kehidupan yang saling berlawanan, namun tak terpisahkan dan saling menyeimbangkan, yaitu: a) kaya dan miskin; b) pandai dan bodoh; c) majikan dan abdi; d) kebaikan (dharma) dan kejahatan (adharma). Pertunjukan dramatari Arja Basur di Desa Adat Tegal tidak hanya berfungsi memberikan hiburan kepada masyarakat penonton, namun juga sekaligus memberikan tuntunan secara batiniah. Nilai-nilai pendidikan karakter yang terkandung di dalamnya ialah nilai religi, nilai etika, dan nilai kasih sayang. Melalui nilai-nilai pendidikan karakter dalam dramatari Arja Basur dapat dijadikan refleksi dan tuntunan dalam upaya membentuk kepribadian manusia agar senantiasa mengaplikasikan nilai-nilai kebaikan serta kebenaran dalam berkehidupan.
\end{abstract}

Kata Kunci: Arja Basur, Dramatari, Nilai Pendidikan Karakter, Desa Adat Tegal

\section{CHARACTER EDUCATION VALUES IN THE DANCE DRAMA OF ARJA BASUR IN TEGAL TRADITIONAL VILLAGE, DARMASABA BADUNG BALI}

\begin{abstract}
Art is the result of human creativity, taste, and initiative that has the values of a philosophy of life. The dance drama of Arja Basur in the Tegal Traditional Village, Darmasaba Badung Bali is one of the rare arts that emerged around 1931. Apart from presenting aesthetic values in its performances, it also contains educational values. The story contains these values, namely through the protagonist and the antagonist. This study aims to examine the functions and values of character education contained in the Arja Basur dance drama. The research method used is qualitative research with data collection techniques through interviews, observations, literature studies, and documentation. The results of the study show that Arja Basur's dance drama contains the conception of rwa bhineda, namely the duality of life that is opposite but inseparable and balances each other, namely: a) rich and poor; b) clever and stupid; c) employer and servant; d) good (dharma) and evil (adharma). The performance of Arja Basur dance drama in the Tegal Traditional Village
\end{abstract}


provides entertainment to the audience and provides inner guidance. The values of character education contained in it are religious values, ethical values, and values of compassion. The values of character education in the Arja Basur dance-drama can be used as a reflection and guidance to shape the human personality so that they always apply the values of goodness and truth in life.

Keywords: Arja Basur, Dance Drama, Character Education Value, Tegal Traditional Village

\section{PENDAHULUAN}

Pendidikan karakter adalah suatu usaha manusia secara sadar dan terencana untuk mendidik serta memberdayakan potensi peserta didik guna membangun karakter pribadinya sehingga dapat menjadi individu yang bermanfaat bagi dirinya sendiri dan lingkungannya (Syamsuddin, 2019: 32). Di tengah derasanya arus globalisasi pada era milenial ini, pendidikan karakter menjadi suatu hal penting yang patut ditanamkan pada generasi muda bangsa agar tumbuh menjadi pribadi-pribadi yang cerdas, santun, kreatif, dan mencerminkan kearifan budaya bangsa. Pendidikan karakter memiliki sifat bidireksional, yaitu pengembangan kemampuan intelektual dan kemampuan moral (Koesoema A, 2010: 115). Dari kutipan di atas dapat dipahami bahwa, pendidikan karakter tidak hanya berperan untuk membentuk pribadi manusia yang cerdas secara intelektual, tetapi juga menekankan pada pembentukan pribadi yang cerdas secara emosional dan sosial. Proses pendidikan karakter tidak hanya dilakukan melalui pendidikan formal saja, namun juga bisa dilakukan melalui kesenian.

Kesenian ialah hasil daya cipta, rasa, dan karsa manusia yang di dalamnya tersirat atau memiliki nilai-nilai falsafah kehidupan. Salah satu bentuk kesenian Bali yang dalam pertunjukannya menyajikan nilai-nilai pendidikan, yaitu dramatari Arja. Arja termasuk kesenian yang kemunculannya cukup tua, yakni pada tahun 1825 ketika upacara kremasi (palebon) Raja tertinggi di Bali, yaitu I Dewa Agung Gede Kusamba dari Klungkung. Ketika itu Raja Badung dan Gianyar mengirimkan penari dan musisi yang membentuk kelompok kombinasi guna menampilkan pertunjukan khusus dan baru pada upacara kremasi tersebut. Pertunjukan itu dinamakan $d a-$ dap yang kemudian lebih dikenal dengan nama Arja. Dramatari Arja kemudian berkembang luas di seluruh Bali menjelang abad 20 (Bandem \& deBoer, 2004: 115). Arja menggunakan dialog yang dinyanyikan dengan tembang macapat. Ada banyak lakon yang digunakan dalam dramatari Arja, salah satunya adalah cerita dengan lakon Basur. Dalam lakon Basur ini menggunakan tembang atau pupuh yang disebut dengan Ginada Basur disamping juga menggunakan tembang-tembang macapat lainnya.

Arja Basur yang ada di Desa Adat Tegal, Darmasaba Badung Bali merupakan salah satu bentuk dramatari yang sarat menyajikan nilai-nilai pendidikan. Hal yang menarik ialah dramatari Arja menyampaikan nilai-nilai pendidikan karakter tersebut lewat ungkapan tembang (nyanyian atau lagu) dan dialog verbal yang diucapkan oleh para tokoh dalam pertunjukan, baik tokoh protagonis maupun tokoh antagonis. Pada pertunjukan dramatari Arja Basur, masyarakat penonton tidak hanya mendapatkan hiburan, namun pendidikan karakter disisipkan agar masyarakat terhibur sekaligus mendapat tuntunan secara batiniah. Keberadaan dramatari Arja Basur di Desa Adat Tegal diperkirakan telah terbentuk sejak tahun 1931 (Astini, 2000: 19). Arja Basur ini telah melalui perjalanan pentas yang sangat panjang dan hingga saat ini (tahun 2021) telah memiliki delapan generasi penari. Pembentukan generasi penari Arja Basur di Desa Adat Tegal dari yang pertama sampai keenam, dilakukan pada tahun 1931, 1933, 1953, 
1961, 1970, dan 1979 (Astini, 2000: 28-33). Selepas tahun 1979, generasi penari yang ketujuh kemudian dibentuk pada tahun 2000 dan generasi kedelapan dibentuk tahun 2018. Dalam 90 tahun perjalananya, nilai-nilai filosofi kehidupan dalam dramatari Arja Basur senantiasa kontekstual untuk dihayati dan diimplementasi dalam kehidupan manusia, dari masa ke masa dalam arus perubahan dinamika zamannya. Pada hakikatnya, nilai filosofi tersebut mengandung nilai-nilai pendidikan sekaligus sebagai refleksi kehidupan yang patut dimaknai oleh setiap insan, guna membentuk karakter diri dan kepribadian yang memahami tata susila, saling mengasihi, dan saling menghargai dalam menjalani kehidupan. Berdasarkan pemaparan di atas, maka penelitian ini bertujuan untuk mengkaji fungsi dan nilai-nilai pendidikan yang terkandung dalam dramatari Arja Basur di Desa Adat Tegal, Darmasaba Badung Bali.

\section{METODE}

Penelitian ini menggunakan metode penelitian kualitatif. Data penelitan dikumpulkan melalui teknik observasi, wawancara, studi kepustakaan, dan dokumentasi. Sumber data yang digunakan, yaitu: 1) Data primer, yakni data-data berupa pernyataan deskriptif yang didapatkan dari para narasumber dan hasil pengamatan terhadap pertunjukan dramatari Arja Basur; 2) Data sekunder, berupa sumber data tertulis dan dokumentasi yang digunakan untuk memperkuat analisis data penelitian. Pada penelitian ini, pengamatan terhadap pertunjukan dramatari Arja Basur dilakukan pada hari Rabu tanggal 19 Mei 2021, pada saat upacara Penyimpenan-Buda Kliwon Pahang/Pegatwakan, di Pura Dalem Gede Desa Adat Tegal, Darmasaba Badung Bali. Informan kunci pada penelitian ini diantaranya ialah: I Made Gari penari senior atau sesepuh Arja Basur yang sekaligus berperan sebagai pelatih Arja Basur di Desa Adat Tegal. Kemudian I Wayan Suteja pemangku di
Pura Dalem Gede Desa Adat Tegal, Darmasaba Badung Bali, tempat dimana Arja Basur ini berada. Pengumpulan data penelitian difokuskan untuk dapat menganalisis fungsi dan nilai-nilai pendidikan yang terkandung dalam dramatari Arja Basur. Data-data yang terkumpul dideskripsikan dengan teknik analisis kualitatif untuk selanjutnya disusun secara sistematis serta ditarik kesimpulan.

\section{HASIL DAN PEMBAHASAN \\ Cerita Basur Sebagai Sumber Lakon Dalam Dramatari Arja Basur di Desa Adat Tegal}

Cerita Basur sebagai sumber lakon dalam dramatari Arja Basur terdapat dalam gaguritan basur yang ditranskripkan dari lontar oleh Made Sanggra. Cerita tersebut ditulis dalam bentuk pupuh atau tembang macapat Ginada Basur. Adapun uraian cerita Basur tersebut, yakni dikisahkan di Banjar Sari terdapat keluarga I Nyoman Karang dengan dua putrinya yang bernama Ni Sukasti dan Ni Rijasa. Istri I Nyoman Karang telah lama meninggal karena diracun dengan cara ilmu hitam oleh tetangganya yang bernama I Gede Rempag. Hal tersebut membuat I Nyoman Karang selalu menasehati putri-putrinya. Kedua anak I Nyoman Karang ini mempunyai sifat yang baik, selalu menuruti perintah ayahnya, tidak itu saja Ni Sukasti sendiri mempunyai wajah yang cantik. Pada keluarga lain, dikisahkan di Banjar Sekar tinggalah I Made Tanu dengan putranya yang bernama I Wayan Tirta. I Wayan Tirta adalah anak yang berbudi baik dan senang menimba ilmu hingga merantau ke negeri seberang. Karena kegemarannya dalam menimba ilmu membuat I Wayan Tirta lupa untuk mencari pasangan kekasih. Hal inilah yang menyebabkan ayahnya I Made Tanu dan pamannya menjadi khawatir, sehingga pada saat Tirta pulang dari menimba ilmu, ayahnya menasehati untuk menikah dan dipilihlah Ni Sukasti untuk menjadi menantunya. Oleh karena ingin me- 
nyenangkan hati orang tuanya maka Tirta pun setuju untuk meminang Ni Sukasti. Berikutnya diceritakan keluarga lainnya, yaitu Jero Gede Basur dengan putranya yang bernama I Wayan Tigaron bersama dengan abdinya ( $p a-$ rekan) yang bernama I Pondal. Keluarga ini tinggal di Banjar Santun. Jero Gede Basur terkenal sebagai raja ilmu hitam (pengiwa) dan kaya raya. Putranya I Wayan Tigaron mempunyai tabiat yang kurang baik sama dengan ayahnya. Tigaron sangat senang dipuji senang memaksakan kehendaknya. I Wayan Tigaron mempunyai parekan yang bernama Punta dan Wijil. Dilain pihak juga disebutkan Ni Subandar dari Banjar Bangsal. Ni Subandar mempunyai putri yang bernama Ni Garu dan mempunyai sifat sedikit gila serta juga senang dipuji. Ni Garu mempunyai penyeroan (pembantu) yang bernama Desak Rai.

Dikisahkan Jero Gede Basur ingin anaknya mempunyai istri dan I Tigaron meminta ayahnya untuk meminang Ni Sukasti untuk menjadi istrinya. Jero Gede Basur pun menyuruh Pondal untuk menyiapkan segala keperluan meminang. Mereka membawa banyak perhiasan, batu permata untuk diserahkan kepada Ni Sukasti. Jero Gede Basur akhirnya berangkat bersama dengan Pondal ke Banjar Sari menuju rumah I Nyoman Karang. Pada saat yang sama I Made Tanu yang merupakan ayah I Wayan Tirta juga berangkat memingan Ni Sukasti akan tetapi dalam perjalanan meminangnya I Made Tanu tidak membawa apa-apa karena mereka bukan berasal dari keluarga yang kaya. Jero Gede Basur lebih dahulu sampai di tempat I Nyoman Karang, Jero Gede Basur dengan nada yang sombong meminta agar Ni Sukasti diserahkan sebagai menantunya. Akan tetapi permintaan Jero Gede Basur tersebut ditangguhkan oleh I Nyoman Karang karena harus membicarakan terlebih dahulu dengan anaknya. Belum selesai pembicaraan mereka datanglah I Made Tanu yang juga bertujuan untuk melamar Ni Sukasti. Kedua keluarga ter- sebut disambut dengan baik oleh I Nyoman Karang. Melihat ada dua keluarga yang melamar Ni Sukasti, maka I Nyoman Karang memanggil anaknya dan diminta untuk memilih siapa yang ia terima untuk dijadikan suami. Ni Sukasti kemudian memilih I Wayan Tirta untuk dijadikan suaminya. Melihat kejadian ini Jero Gede Basur merasa tersinggung, lalu pulang tanpa permisi dengan menahan marah dan dendam.

Setibanya Jero Gede Basur di rumahnya, I Wayan Tigaron menanyakan hasil dari pinangan ayahnya. Dengan muka masam ayahnya menceritakan hal yang terjadi. I Wayan Tigaron pun marah kepada ayahnya yang telah gagal meminang Ni Sukasti, hingga berniat untuk membunuh diri. Melihat keinginan anaknya yang begitu besar, Jero Gede Basur menyarankan I Tigaron untuk menculik Ni Sukasti. Tigaron menyusun rencana dengan kedua parekannya untuk menculik Ni Sukasti di pancoran (tetamanan) pada saat Ni Sukasti mandi. Mereka pun berangkat kepancoran tempat Sukasti mandi. Di tengah jalan mereka bertemu dengan Ni Garu dan Desak Rai. Dalam pertemuan tersebut Ni Garu jatuh cinta dengan I Wayan Tigaron, namun Tigaron menolaknya dan menyuruh Ni Garu untuk pulang. Ni Garu yang keras kepala tidak mau pulang dan terus memaksa Tigaron untuk memperistri dirinya. Tigaron kemudian menjadi marah dan menghajar Ni Garu. Ni Garu pun kemudian pulang dengan perasaan sedih, sakit, dan marah. Tigaron kembali melanjutkan perjalanannya. Sesampainya dipancoran Tigaron bertemu dengan Ni Sukasti dan menculiknya, namun kemudian Tigaron dihadang oleh Tirta dan pamannya. Akhirnya terjadi pertarungan antara Tirta dengan Tigaron. Pertarungan tersebut dimenangkan oleh Tirta. Tigaron kemudian pulang kerumahnya dengan dipapah oleh kedua parekannya. Setelah sampai dirumah Tigaron menemui ayahnya dan menceritakan yang terjadi padanya. Melihat keadaan anakya, Jero Gede 
Basur sangat marah.

Hari menjelang malam Jero Gede Basur memanggil anak buahnya untuk diajak mencelakakan keluarga I Nyoman Karang dan hendak membunuh Ni Sukasti. Malam hari Jero Gede Basur pergi ke kuburan membawa sesajen untuk menghidupkan kesaktian yang Ia miliki. Benarpun Ni Sukasti menjadi jatuh sakit dan semua keluarga I Nyoman Karang dan I Made Tanu menjadi panik. Mereka akhirnya merencanakan untuk mencari balian (dukun) untuk mengobati Ni Sukasti. Setelah lama melakukan perjalanan akhirnya I Made Tanu dan saudaranya menemukan seorang dukun. Akan tetapi dukun yang mereka temui ternyata dukun palsu yang hanya mata duitan dan mengakui dirinya sakti. Dukun tersebut menyetujui untuk menyembuhkan Ni Sukasti dengan sesari (upah) yang telah ditentukan. Sesampai dukun tersebut dirumah Ni Sukasti, ia mencoba untuk menyembuhkannya, namun bukannya Ni Sukasti menjadi sembuh, malahan dukun tersebut yang mati dicelakai oleh I Gede Basur. Ditengah kepanikan yang dialami keluarga I Nyoman Karang, datanglah orang tua yang bernama I Kaki Balian yang juga masih kerabat I Nyoman Karang untuk membantu mereka keluar dari kesusahan. Kaki Balian memberitahukan bahwa yang menjadi penyebab dari sakitnya Ni Sukasti ialah karena perbuatan dari Jero Gede Basur. Dengan mengucapkan mantra-mantra, kemudian I Kaki Balian menunjukkan yang membuat sakit Ni Sukasti dan mengembalikannya kepada pemiliknya. Akhirnya Ni Sukasti pun dapat disembuhkan.

Berdasarkan uraian cerita Basur di atas, sebagai sumber lakon dalam pertunjukan dramatari Arja Basur terdapat tokoh-tokoh dengan sifat dan karakternya masing-masing, ada yang baik (protagonis) ada pula yang buruk (antagonis) dan sejatinya semua itu merefleksikan kehidupan. Nilai-nilai yang terkandung dalam cerita dan tokoh tersebut, dapat dijadikan sebagai pembelajaran dalam men- didik karakter bagi setiap individu agar senantiasa dapat menjadi pribadi yang positif dan memiliki nilai-nilai kepatutan dalam melakukan setiap tindakan. Dalam pendidikan ada delapan belas (18) nilai karakter yang penting ditanamkan yang bersumber dari Agama, Pancasila, Budaya, dan Tujuan Pendidikan Nasional, yaitu: 1) religius, 2) jujur, 3) toleransi, 4) disiplin, 5) kerja keras, 6) kreatif, 7) mandiri, 8) demokratis, 9) rasa ingin tahu, 10) semangat kebangsaan, 11) cinta tanah air, 12) menghargai prestasi, 13) bersahabat/komunikatif, 14) cinta damai, 15) gemar membaca, 16) peduli lingkungan, 17) peduli sosial, 18) tanggung jawab (Kemendiknas, 2011). Apabila dicermati dengan seksama, nilai karakter yang dapat dipetik dalam cerita Basur ini ialah nilai religius, jujur, toleransi, bersahabat/komunikatif, cinta damai, peduli sosial, tanggung jawab. Dari cerita ini kita bisa belajar banyak tentang karakter yang ideal diterapkan agar terwujud harmonisasi kehidupan antara manusia dengan Tuhan Sang Pencipta, manusia dengan alam, dan manusia dengan sesama manusia. Pada dramatari Arja yang menggunakan lakon Basur ini terlihat jelas konsep dualitas kehidupan, yakni konsep rwa bhineda, dua sisi kehidupan yang berbeda, saling berlawanan, namun tak terpisahkan dan saling menyeimbangkan, yakni: a) Kaya (I Gede Basur) dan miskin (I Made Tanu); b) I Wayan Tirta pemuda yang pandai, paham tata susila/sopan, dan tampan sedangkan I Wayan Tigaron pemuda yang bodoh, ugal-ugalan, keras kepala/suka memaksakan kehendak; c) Ada majikan dan ada abdi; d) Kebaikan (dharma) dan kejahatan (adharma).

Arja Basur merupakan sebuah kesenian dramatari bertembang dengan elemen-elemen pertunjukan yang sangat kompleks, terdiri dari tembang (vokal), tari, drama, musik serta tata rias dan busana. Dramatari Arja Basur di Desa Adat Tegal, jika dilihat dari jumlah penarinya tergolong sebagai Arja Gede karena jumlah penarinya lebih dari 12 orang, 
yakni 17 orang penari, dengan rincian sepuluh orang penari putra dan tujuh orang penari putri. Untuk menampilkan tokoh dalam dramatari Arja Basur, penari tidak hanya dituntut mampu menari dengan teknik gerak yang baik, namun yang tak kalah penting adalah mampu matembang dan memiliki kualitas vokal yang baik. Prinsip keindahan Arja ialah ngigel matembang (Dibia, 2012: 5). Pernyataan tersebut menegaskan, bahwa tembang menjadi elemen utama yang bersifat vital dalam pertunjukan Arja Basur karena setiap gerak laku penari di atas pentas, berdasarkan atas tembang yang dinyanyikan oleh masing-masing penari sesuai tokoh yang diperankan. Adapun jenis-jenis tembang atau $p u-$ puh yang biasanya digunakan dalam dramatari Arja Basur di Desa Adat Tegal ialah pupuh ginada, pupuh sinom, pupuh dangdang, pupuh durma, pupuh pangkur, dan pupuh maskumambang. Pembentukan penari dramatari Arja Basur di Desa Adat Tegal yang terbaru dilakukan pada tahun 2018. Saat ini (tahun 2021) para penarinya rata-rata menginjak masa remaja, dengan usia berkisar antara 15 tahun sampai dengan 20 tahunan. Dari pengamatan di lokasi penelitian, komposisi penari tersebut berdampak pada munculnya rasa ketertarikan dan meningkatnya minat apresiasi masyarakat penonton, khususnya para generasi muda untuk menyaksikan pertunjukan Arja Basur. Melalui interaksi yang terjadi antara tontonan (pertunjukan Arja Basur) dengan penonton inilah nilai-nilai pendidikan yang terkandung dalam dramatari Arja Basur dapat tersampaikan dan diresapi sebagai tuntunan hidup.

\section{Fungsi Dramatari Arja Basur di Desa Adat Tegal}

Setiap bentuk pertunjukan karya seni, khususnya tari memiliki fungsi masing-masing dalam kehidupan masyarakat. Seminar Seni Sakral dan Profan Bidang Tari tahun 1971, mengklasifikasikan fungsi tari
Bali menjadi menjadi tiga, yaitu 1) wali ialah sajian seni yang bersifat sakral; 2) bebali ialah sajian seni sebagai pelengkap upacara; dan 3) balih-balihan ialah sajian seni untuk hiburan atau bersifat profan (Bandem, 1996: 50). Berdasarkan klasifikasi tari di atas, dramatari Arja Basur di Desa Adat Tegal, Darmasaba Badung Bali berfungsi sebagai seni balih-balihan. Dalam hal ini, pertunjukan Arja Basur bertujuan untuk memberikan hiburan kepada masyarakat atau penonton dalam kaitannya dengan kegiatan upacara keagamaan atau piodalan di pura maupun perayaan atau festival seni. Walaupun demikian, dramatari Arja Basur ini dikeramatkan oleh masyarakat setempat, karena dalam pembentukan penarinya melalui proses ritual pawinten dan mesakapan. Upacara ini bertujuan untuk membersihkan diri para penari dari energi-energi negatif, sekaligus memohon anugerah kepada Tuhan/Ida Sang Hyang Widhi Wasa agar para penari diberikan keselamatan dan kekuatan taksu. Selain itu, pementasan Arja Basur ini juga selalu menghadirkan sasuhunan Ida Ratu Mas Ayu yang berwujud rangda dan disakralkan di Pura Dalem Gede di desa setempat. Rangda Sakral tersebut ditarikan oleh penari khusus yang disebut juru pundut, yakni merupakan seorang penari laki-laki dewasa yang telah melalui prosesi ritual atau sakralisasi.

Berikutnya, dramatari Arja Basur ini juga dapat berfungsi sebagai media pendidikan. Dalam konteks ini, pertunjukan Arja Basur merupakan sebuah tonton sekaligus tuntunan yang membawa atau menyajikan falsafah kehidupan. Nilai-nilai kehidupan disajikan lewat tembang dan dialog dari para tokoh dalam cerita Basur, yang diperankan oleh para penari saat pementasan. Ini berarti pertunjukan Arja Basur tidak semata untuk menghibur dan menyajikan keindahan, namun juga menjadi pengantar atau pembawa pesan moral untuk dikomunikasikan dan ditangkap maknanya oleh penonton. Dibia (2012: 3) menje- 
laskan, bahwa sajian seni pertunjukan hendaknya dapat memberikan kenimatan berkualitas bayu, sabda, dan idep. Artinya, sebuah sajian seni pertunjukan secara seimbang harus dapat menyuguhkan kenikmatan estetis yang dapat dinikmati dengan mata, telinga, dan pikiran. Bila dicermati dalam pertunjukan Arja Basur, sajian keindahan berkualitas bayu dapat dinikmari dari rangkaian gerak tari nan ritmis yang diungkapkan oleh para penari. Keindahan berkualitas sabda dapat dinikmati lewat lantunan tembang dan dialog yang diucapkan oleh para penari serta irama musikal. Kemudian keindahan berkualitas idep dapat dihayati dari pesan-pesan (filsafat) yang terkandung dibalik cerita Basur yang disajikan melalui tambang. Sebagai media pendidikan, pertunjukan Arja Basur mengajak para penonton untuk dapat memaknai hakikat hidup berkaitan dengan baik dan buruk serta benar dan salah yang selalu berdampingan dalam kehidupan. Dengan demikian, harapannya setiap insan dapat memegang teguh nilai-nilai moral dan etika dalam bertindak dan mengambil keputusan secara bijaksana.

\section{Nilai-Nilai Pendidikan Karakter dalam Dramatari Arja Basur di Desa Adat Tegal}

Berbicara tentang nilai-nilai pendidikan dalam kesenian, terlebih dahulu tentu harus kita awali dengan penjelasan apa yang dimaksud pendidikan karakter. Pendidikan merupakan usaha secara sadar yang ditujukan untuk pengembangan diri manusia secara integral dan utuh, melalui berbagai macam dimensi yang dimiliki (religis, moral, sosial, kultural, personal, relasional) demi proses penyempurnaan dirinya secara terus menurus dalam memaknai hidup dan sejarahnya di dunia ini dalam kebersamaan dengan orang lain (Koesoema A, 2010: 123). Sedangkan karakter merupakan kondisi dinamis struktur antropologis individu yang tidak sekedar berhenti atas determinasi koratinya, melainkan juga sebuah usaha hidup untuk menjadi semakin integral mengatasi determinasi alam dalam dirinya untuk proses penyempurnaan diri secara terus-menerus (Koesoema A, 2010: 123). Dari penjelasan ini dapat dipahami, bahwa pendidikan karakter merupakan sebuah usaha pembinaan dan pengembangan potensi diri yang bertujuan untuk membentuk pribadi manusia agar mampu memahami dan memaknai nilai-nilai kebenaran serta mengimplementasikannya dalam aktivitas kehidupan sosial di masyarakat. Pendidikan karakter menekankan pada penguatan intelektualitas dan integritas, agar pribadi manusia mampu bertindak berlandaskan nilai moral dan bertanggung jawab sehingga dapat membawa nilai-nilai kebaikan dan kebenaran dalam masyarakat. Upaya pendidikan karakter tidak hanya dapat dilakukan melalui pendidikan formal, namun juga bisa melalui pendidikan non formal, bahkan nilai-nilai pendidikan tersebut juga bisa diberikan atau disisipkan lewat aktivitas kesenian. Sebagai bentuk presentasi estetis kesenian tidaklah melulu berkutat tentang persoalan keindahan, namun berkesenian juga dapat melueskan jiwa dan pemahaman seseorang dengan menghayati pesan-pesan yang ada di dalamnya.

Kesenian sebagai sebuah ungkapan ekspresi estetis sejatinya menyajikan atau mengkomunikasikan persoalan-persoalan kehidupan yang kontekstual dan aktual serta di dalamnya terkandung nilai-nilai kehidupan dan pesan moral yang menandakan bobot kesenian itu sendiri. Gagasan dan pesan yang disampaikan dalam pertunjukan dramatari Arja Basur di Desa Adat Tegal ialah konsepsi Rwa Bhineda dalam Hindu Bali yang menyangkut tentang kebaikan dan kejahatan, kaya dan miskin. Cerita Basur ini juga mengandung nilai-nilai cinta kasih, etika dan sopan santun dalam kehidupan bermasyarakat. Cerita Basur yang berkembang di masyarakat memiliki pembelajaran teks dan konteks. Teks berkaitan dengan cerita Basur sebagai sumber lakon pertunjukan Arja Basur. Sedangkan kon- 
teksnya ialah nilai moral yang ada di dalamnya perlu dipahami oleh semua lapisan masyarakat. Seperti halnya cerita Basur, dalam konteks kebaikan (baik) dan Kejahatan (buruk) direfleksikan melalui tokoh I Nyoman Karang dan I Gede Basur. I Nyoman Karang adalah tokoh dengan karakter baik, bijaksana, dan bertata krama yang perlu dijadikan panutan karena menjalani hidup dengan penuh cinta kasih, melaksanakan ajaran yang menjaga keharmonisan antar sesama. Akan tetapi berbeda halnya dengan I Gede Basur yang angkuh, sombong, dan pendendam, menuruti segala keinginan anaknya bahkan sampai menggunakan ilmu hitam (black magic) untuk membalaskan kekecewaan serta dendamnya pada Ni Sukasti karena pinangannya ditolak. Sisi baik dan buruk ini menjadi pesan dalam cerita agar mampu kita hayati, maknai, dan diaplikasikan dalam hidup untuk keharmonisan. Adapun tokoh I Nyoman Karang dan Ni Sukasti dapat dilihat pada gambar di bawah ini.

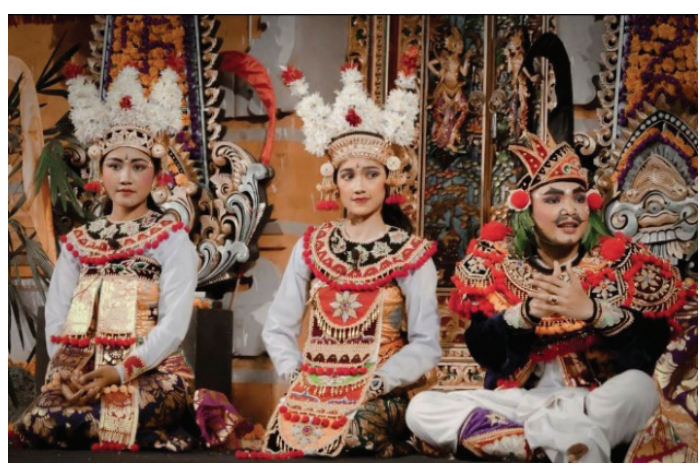

Gambar 1. Tokoh I Nyoman Karang (kanan) digambarkan sebagai sosok orang tua yang bijaksana, bersama putrinya Ni Sukasti (tengah) digambarkan sebagai putri yang berparas cantik, jujur, dan sopan, didampingi oleh Condong (kiri) digambarkan sebagai emban yang setia dan bertatakrama dalam pertunjukan Arja Basur di Desa Adat Tegal dibawakan oleh generasi penari tahun 2018

Foto: Azimuth Dewata, 2019

Berikutnya dalam pertunjukan Arja Basur ini juga menampilkan tokoh I Wayan Tirta yang digambarkan sebagai pemuda yang tumbuh di keluarga miskin, namun ia merupakan pemuda yang cerdas, berkarakter jujur, memahami tata krama, etika, dan sopan santun. Berbeda halnya dengan I Wayan Tigaron yang digambarkan sebagai pemuda kaya raya, tetapi memilik karakter yang angkuh, ugal-ugalan, senang dipuji, dan suka memaksakan kehendak. I Wayan Tirta selalu berbuat sesuai norma dan etika, menghargai berkah alam, serta berusaha untuk menjaga dan mensyukuri sekecil apapun berkah itu. Sebaliknya I Wayan Tigaron senang berbuat seenak hatinya karena merasa kaya, seolah-olah segala sesuatu dapat dibeli. Melalui pertunjukan Arja Basur ini, dapat dipahami bahwa kebenaran ialah dasar utama dalam menjalani hidup dengan dilandasi cinta kasih dan harta menjadi pendukung untuk memenuhi kebutuhan hidup. Jika semua itu sudah terlaksana dengan seimbang maka kebahagiaan pasti terjadi. Cerita Basur sesungguhnya memberikan manusia sasuluh hidup yang dapat dijadikan sebagai tuntunan agar senantiasa dapat membawa nilai-nilai kebenaran dan kebaikan dalam kehidupan. Adapun tokoh I Gede Basur dan I Wayan Tigaron dapat dilihat pada gambar berikut ini.

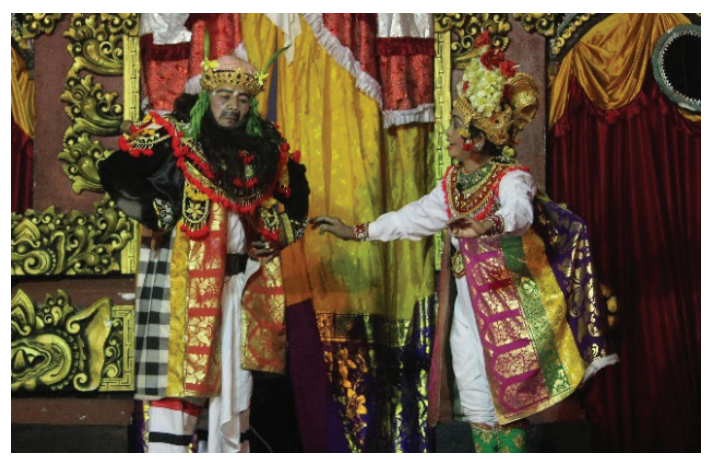

Gambar 2. Tokoh I Gede Basur (kiri) digambarkan sebagai sosok yang angkuh, sombong, dan menguasai ilmu hitam serta tokoh I Wayan Tigaron (kanan) digambarkan sebagai pemuda yang keras kepala, arogan, dan suka memaksakan kehendak dalam pertnjukan Arja Basur di Desa Adat Tegal dibawakan oleh generasi penari tahun 1979 (Basur) dan 1963 (Tigaron)

Foto: I Wayan Adi Gunarta, 2017 
Pertunjukan dramatari Arja Basur di Desa Adat Tegal tidak hanya memberikan hiburan kepada masyarakat penonton, namun sekaligus juga memberikan tuntunan secara batiniah. Nilai-nilai pendidikan karakter dalam dramatari Arja Basur dapat dijadikan sebagai refleksi dan tuntunan dalam upaya membentuk kepribadian manusia agar senantiasa membawa nilai-nilai kebaikan serta kebenaran dalam berkehidupan. Adapun nilai-nilai pendidikan tersebut adalah sebagai berikut:

\section{Nilai Religi}

Seni dalam kehidupan religius masyarakat Hindu Bali tidaklah dapat terpisahkan. Seni selalu hadir dalam setiap perayaan upacara-upacara keagaman baik sebagai sarana upacara maupun sarana hiburan. Sejak zaman primitif, seni banyak mengambil peranan dalam aktivitas atau tujuan yang bersifat sosial maupun religius (Read, 1970: 8-22 dalam Hadi, 2006: 256). Begitu pula halnya dengan dramatari Arja Basur di Desa Adat Tegal, Darmasaba Badung Bali yang di dalamnya mengandung nilai-nilai religi dan magis mulai dari proses pembentukan penari hingga pertunjukan berlangsung. Setiap melakukan aktivitas berkesenian para penari ataupun masyarakat pendukungnya selalu mengawalinya dengan persembahan dan persembahyangan untuk memohon doa restu, kelancaran, dan kekuatan taksu. Hal ini sesungguhnya mendidik setiap individu, khususnya yang terlibat di dalam pertunjukan untuk menumbuhkan sikap religius dan mengembangkan nilai-nilai spiritualitas agar taat dengan ajaran agama. Berkesenian tidak semata hanya untuk menyajikan keindahan, namun juga mengajarkan kita berkonsentrasi dan memberikan pelayanan lewat persembahan keindahan secara bersungguh-sungguh, untuk menghubungkan diri dengan dewa-dewi agar memperoleh perlindungan. Pertunjukan dramatari Arja Basur ini juga selalu menghadirkan sosok Rangda sakral yang disthanakan di Pura Dalem Gede
Desa Adat Tegal dan oleh masyarakat setempat disebut dengan Ida Ratu Mas Ayu. Kehadiran rangda sakral ini dipercayai dapat memberikan perlindungan dan daya kharismatik kepada para penari selama pertunjukan. Tak jarang pula, ketika rangda sakral ini masolah (menari) pada pertunjukan Arja Basur terdapat penonton yang mengalami trance. Adanya trance ini bisa dikatakan sebagai petanda, bahwa kekuatan adi kodrati itu benar-benar hadir dalam pertunjukan sehingga dapat semakin meneguhkan keyakinan masyarakat atas perlindungan yang diberikan oleh Tuhan Sang Pencipta.

\section{Nilai Etika}

Manusia sebagai makhluk sosial hendaknya memahami nilai etika dan tata susila agar tercipta keharmonisan dalam pergaulannya di kehidupan sosial masyarakat. Pada hakikatnya, manusia tidaklah dapat hidup sendiri, tetapi saling membutuhkan dan saling berinteraksi satu sama lain dalam kelompok masyarakat. Bila dicermati, pertunjukan dramatari Arja Basur menyampaikan nilai-nilai etika yang dapat dihayati dan dijadikan sebagai pelajaran oleh masyarakat dalam menjalani kehidupan. Adapun nilai-nilai etika yang terdapat dalam pementasan Arja Basur, yaitu:

\section{a. Sopan Santun \\ Nilai sopan santun dalam pertunjukan} dramatari Arja Basur dapat dipetik dari tokoh I Wayan Tirta yang merupakan putra dari I Made Tanu. Tirta ialah seorang pemuda yang giat belajar dan memahami tata krama dalam berinteraksi sosial, yakni menghormati orang tua, berbuat dan bertutur kata yang baik/halus, serta berbudi pekerti luhur. Nilai-nilai tersebut merupakan refleksi yang sepatutnya diimplementasikan dalam kehidupan sosial bermasyarakat. Dengan demikian, dalam interaksi sosial antar personal di masyarakat akan terjalin komunikasi yang baik dan saling menghargai berlandaskan rasa tanggung 
jawab sehingga terwujud kedamaian. Nilai kesopanan ini sangat penting dijaga dan $\mathrm{d} d \mathrm{da}-$ lam kehidupan bermasyarakat agar tidak tergerus oleh perkemebangan zaman.

\section{b. Kejujuran dan Tanggung Jawab}

Sikap jujur dan bertanggung jawab ialah nilai karakter yang sangat penting ditanamkan pada diri dan mencerminkan akhlak seseorang. Pada pertunjukan Arja Basur, nilai-nilai pendidikan ini dapat kita hayati dan teladani dari tokoh I Nyoman Karang yang digambarkan sebagai orang tua yang bijaksana, jujur, dan bertanggung jawab yang tercermin dalam tutur kata dan tindakannya. Nilai-nilai tersebut ia tanamkan dalam membesarkan putri-putrinya, yakni Ni Sukasti dan Ni Rijasa sehingga tumbuh menjadi anak yang jujur dan santun. Nilai kejujuran dan tanggung jawab yang tercermin dari tokoh ini merupakan pembelajaran yang patut diaktualisasikan dalam diri dan direalisasikan dalam setiap tindakan tindakan dan pengambilan keputusan.

\section{c. Pengendalian Diri}

Di dalam pertunjukan dramatari Arja Basur, tokoh I Tigaron yang digambarkan sebagai sosok pemuda yang urakan, sombong, dan suka memaksakan kehendak, sejatinya merupakan sebuah refleksi bagi setiap orang agar dalam menjalani hidup hendaknya tidak berpolah seperti I Tigaron. I Tigaron suka menghalalkan segala cara untuk mencapai keinginannya, namun pada akhirnya menemui kegagalan. Dalam hal ini, nilai yang dapat kita pelajari, bahwa pengendalian diri penting ditanamkan dalam diri setiap orang agar dapat mengontrol setiap tindakan yang dilakukan, didasari oleh pertimbangan dan nilai-nilai kebenaran sehingga dapat dipertanggung jawabkan secara moral dan etik.

\section{d. Kebersamaan}

Nilai kebersamaan ini tampak dalam proses persiapan, pertunjukan, hingga setelah berakhirnya pertunjukan Arja Basur yang melibatkan berbagai komponen masyarakat pendukung, yakni penari, penabuh/sekaa gong, penyarikan, pemangku, dan juga masyarakat lainnya. Dalam hal ini seluruh komponen tersebut bekerjasama saling bergotong royong menyiapkan sarana pementasan seperti banten atau sesajen, tata rias dan busana, tata panggung, sound system, dan yang lainnya. Dari hasil pengamatan di lokasi penelitian, berbagai sarana pemetasan tersebut dikerjakan secara bersama-sama dengan penuh kesadaran dan tulus ikhlas sesuai dengan tugas masing-masing. Secara tidak langsung hal ini dapat mengukuhkan nilai sosial dan semangat gotong-royong sebagai media pendidikan budaya yang ditumbuhkembangkan oleh masyarakat Desa Adat Tegal.

\section{Nilai Kasih Sayang}

Kasih sayang merupakan sikap dan perasaan saling mengasihi yang dalam konteks ini ditekankan pada nilai kasih sayang diantara sesama manusia. Pada pertunjukan dramatari Arja Basur di Desa Adat Tegal, Darmasaba Badung Bali, nilai kasih sayang terdapat pada setiap adegan patemon (pertemuan) tokoh atau keluarga berikut, yakni: 1) Keluarga I Made Tanu: I Made Tanu sangat bangga serta menyayangi putranya I Wayan Tirta yang cerdas dan taat pada orang tua; 2) Keluarga I Gede Basur: I Gede Basur begitu menyayangi putranya I Wayan Tigaron, bahkan karena saking sayangnya, Basur rela malakukan segala cara untuk memenuhi keinginan I Tigaron; 3) Keluarga I Nyoman Karang: Kasih sayang I Nyoman Karang terhadap putrinya Ni Sukasti dapat dilihat dari sikapnya dalam menjaga dan merawat putrinya dengan penuh kesabaran; 4) Keluarga Ni Subandar: Ni Subandar selalu menyanjung dan menyayangi putrinya Ni Garu, meskipun sifat dan tingkahnya sedikit gila. Pada pembahasan ini, salah satu tembang dalam Arja Basur yang menyiratkan nilai 
kasih sayang, dapat disimak pada tembang berikut ini.

Tabel 1. Pupuh dan Terjemahannya

\begin{tabular}{|c|c|}
\hline Pupuh Ginada & Terjemahan \\
\hline I Nyoman Karang & I Nyoman Karang ber- \\
\hline angucap, & kata, \\
\hline $\begin{array}{l}\text { Uduh dewa sang ayu } \\
\text { luwih, }\end{array}$ & $\begin{array}{l}\text { Wahai putriku yang } \\
\text { cantik, }\end{array}$ \\
\hline Eda dewa lunga ejoh, & $\begin{array}{l}\text { Janganlah engkau per- } \\
\text { gi jauh-jauh, }\end{array}$ \\
\hline Atin bapa jumah ibuk, & $\begin{array}{l}\text { Ayah di rumah menja- } \\
\text { di gelisah, }\end{array}$ \\
\hline I Dewa tuara cingak & Kalau ayah tidak meli- \\
\hline bapa, & hatm \\
\hline Lali-lali, & Nanti lupa diri, \\
\hline $\begin{array}{l}\text { Kudiang bapa mega- } \\
\text { rapan (Wawancara, I }\end{array}$ & $\begin{array}{l}\text { Bagaimana ayah bisa } \\
\text { bekerja. }\end{array}$ \\
\hline $\begin{array}{l}\text { Wayan Sadia: } 12 \text { Sep- } \\
\text { tember 2021) }\end{array}$ & \\
\hline
\end{tabular}

Tembang di atas mencerminkan nilai kasih sayang orang tua (I Nyoman Karang) terhadap putrinya (Ni Sukasti). Curahan kasih sayang yang tulus dari orang tua kepada anak, tentu sebaliknya akan membangun curahan kasih sayang yang sama pula dari anak kepada orang tuanya. Nilai kasih sayang ini tidaklah terbatas pada hubungan orang tua dengan anak. Dalam implementasinya, nilai kasih sayang berlaku dan penting ditanamkan dalam kehidupan bersama, baik diantara manusia dengan sesama manusia, manusia dengan alam, serta manusia dengan Tuhan. Dengan demikian, implementasi nilai kasih sayang dalam kehidupan akan menciptakan keharmonisan, baik di lingkungan keluarga maupun dalam bermasyarakat.

\section{KESIMPULAN}

Kesenian ialah hasil daya cipta, rasa, dan karsa manusia yang di dalamnya tersirat atau memiliki nilai-nilai falsafah kehidupan. Dramatari Arja Basur yang ada di Desa Adat Tegal, Darmasaba Badung Bali merupakan salah satu bentuk kesenian langka yang dalam pertunjukannya menyajikan nilai-nilai pendidikan. Arja Basur di Desa Adat Tegal muncul sekitar tahun 1931 dan memiliki fungsi, yakni 1) Sebagai seni balih-balihan, bertujuan untuk memberikan hiburan kepada masyarakat; dan 2) Sebagai media pendidikan, dalam konteks ini, pertunjukan Arja Basur merupakan sebuah tonton sekaligus tuntunan yang menyajikan falsafah kehidupan. Hal yang menarik ialah nilai-nilai pendidikan karakter disampaikan lewat ungkapan tembang (nyanyian atau lagu) dan dialog verbal yang diucapkan oleh para tokoh dalam pertunjukan, baik tokoh protagonis maupun tokoh antagonis. Pendidikan karakter merupakan sebuah usaha pembinaan dan pengembangan potensi diri yang bertujuan untuk membentuk pribadi manusia agar mampu memahami dan memaknai nilai-nilai kebenaran serta mengimplementasikannya dalam aktivitas kehidupan sosial di masyarakat. Pendidikan karakter menekankan pada penguatan intelektualitas dan integritas, agar pribadi manusia mampu bertindak berlandaskan nilai moral dan bertanggung jawab sehingga dapat membawa nilai-nilai kebaikan dan kebenaran dalam masyarakat.

Dramatari Arja Basur ini memuat konsepsi rwa bhineda, yakni dualisme kehidupan yang saling berlawanan, namun sesungguhnya saling menyeimbangkan dan merupakan satu kesatuan, yakni: a) kaya dan miskin; b) pandai dan bodoh; c) majikan dan abdi; dan d) kebaikan (dharma) dan kejahatan (adharma). Nilai-nilai pendidikan karakter yang ada dalam dramatari Arja Basur dapat dijadikan sebagai refleksi dan pelajaran yang penting diimplementasikan pada diri dalam upaya membentuk dan membina kepribadian manusia yang berakhlak dalam kehidupan bermasyarakat. Adapun nilai-nilai pendidikan tersebut yaitu: 1) Nilai Religi, 2) Nilai Etika, meliput sopan santun, kejujuran dan tanggung jawab, pengendalian diri, serta kebersaamaan; dan 3) Nilai kasih sayang. Pada haki- 
katnya, nilai-nilai pendidikan karakter yang terkandung pada dramatari Arja Basur mencerminkan nila-nilai luhur yang bersumber dari budaya Indonesia serta dapat dijadikan sebagai landasan dalam membentuk watak atau kepribadian generasi muda dan peradaban bangsa yang bermartabat serta mencerdaskan kehidupan bangsa.

\section{DAFTAR PUSTAKA}

Astini, Siluh Made. 2000. "Lakon Basur Dalam Pertunjukan Arja Di Desa Tegal Darmasaba Bali". Tesis Program Pascasarjana Universitas Gajah Mada Yogyakarta.

Bandem, I Made. 1996. Etnologi Tari Bali. Yogyakarta: Kanisius.

Bandem, I Made, dan Fredrik Eugane deBoer. 2004. Kaja dan Kelod: Tarian Bali dalam Transisi. Yogyakarta: Badan Penerbit ISI Yogyakarta.

Dibia, I Wayan. 2012. Geliat Seni Pertunjukan Bali. Denpasar: Arti Foundation. . 2017. Arja Anyar: Seni Tradisi Yang Dibarukan. Denpasar: Cakra Press.

Hadi, Y. Sumandiyo. 2006. Seni Dalam Ritual Agama. Yogyakarta: Pustaka.

Kemendiknas. 2011. Panduan Pelaksanaan Pendidikan Karakter. Jakarta: Badan Penelitian dan Pengembangan Pusat Kurikulum dan Perbukuan.

Koesoema A, Doni. 2010. Pendidikan Karakter: Strategi Mendidik Anak di Zaman Global. Jakarta: Grasindo.

Moleong, Lexy J. 2011. Metodologi Penelitian Kualitatif (Edisi Revisi). Bandung: PT. Remaja Rosdakarya.

Sanggra, I Made. Tanpa Tahun. Gaguritan Basur (Ditranskripsikan Dari Lontar). Denpasar: Cempaka 2 Denpasar.

Soedarsono, R.M. 2002. Seni Pertunjukan Indonesia di Era Globalisasi. Yogyakarta: Gadjah Mada University Press.

Sumadi, I Gusti Made. 2017. "Pementasan
Arja Basur Sakral Di Pura Dalem Nataran Sari Desa Punggul Kecamatan Abiansemal Kabupaten Badung" Dalam Jurnal Penelitian Agama Hindu, Vol. 1, No. 1 Mei 2017, Hal 45-52. Denpasar: IHDN Denpasar.

Syamsuddin. 2019. "Pembentukan Karakter Siswa Berbasis Pendidikan Seni dan Budaya di Man Palu" Dalam Guru Tua: Jurnal Pendidikan dan Pembelajaran, Vol. 2, No. 1, Mei 2019, Hal. 29-36. Palu: Fakultas Keguruan dan Ilmu Pendidikan Universitas Alkhairaat Palu.

\section{DAFTAR INFORMAN}

Gari, I Made. (82 th). Seniman \& Penari Arja Basur (Wijil/Kartala Tigaron) generasi tahun 1953, wawancara tanggal 23 Juni 2021 di rumahnya, Banjar Bucu, Desa Darmasaba, Kecamatan Abiansemal, Kabupaten Badung.

Leseg, Ni Made. (73 th). Penari Arja Basur (Tirta) generasi tahun 1963, wawancara tanggal 23 Juni 2021 di rumahnya, Banjar Taman, Desa Darmasaba, Kecamatan Abiansemal, Kabupaten Badung.

Pageh, I Ketut. (58 th). Penari Arja Basur (Basur) generasi tahun 1979, wawancara tanggal 23 Juni 2021 di rumahnya, Banjar Gulingan, Desa Darmasaba, Kecamatan Abiansemal, Kabupaten Badung.

Yasa, Si Gede Nyoman. (69 th). Bendesa Adat Tegal periode 1994-2004, wawancara tanggal 23 Juni 2021 di rumahnya, Banjar Tengah, Desa Darmasaba, Kecamatan Abiansemal, Kabupaten Badung.

Suteja, I Wayan. (53 th). Pemangku Pura Dalem Gede Desa Adat Tegal, wawancara tanggal 24 Juni 2021 di Pura Dalem Gede, Desa Adat Tegal, Desa Darmasaba, Kecamatan Abiansemal, Kabupaten Badung.

Getar, Ni Wayan. (76 th). Penari Calonarang (Galuh) \& Arja Basur (Sukasti) generasi 
tahun 1963, wawancara tanggal 30 Juni 2021 di rumahnya, Banjar Gulingan, Desa Darmasaba, Kecamatan Abiansemal, Kabupaten Badung.

Andeg, Ni Ketut. (73 th). Penari Arja Basur (Tigaron) generasi tahun 1963, wawancara tanggal 30 Juni di rumahnya, Banjar Telanga, Desa Darmasaba, Kecamatan Abiansemal, Kabupaten Badung.

Sukerti, Si Luh Nyoman. (52 th). Penari Arja Basur (Sukasti) generasi tahun 1979, wawancara tanggal 30 Juni 2021 di rumahnya, Banjar Tengah, Desa Darmasaba, Kecamatan Abiansemal, Kabupaten Badung.
Kari, I Wayan. (63 th). Penyarikan Pura Dalem Gede Desa Adat Tegal, wawancara tanggal 30 Juni 2021 di rumahnya, Banjar Gulingan, Desa Darmasaba, Kecamatan Abiansemal, Kabupaten Badung.

Sadia, I Wayan. (62th). Penari Arja Basur (Nyoman Karang) generasi tahun 1979, wawancara tanggal 12 September 2021 di rumahnya, Banjar Gulingan, Desa Darmasaba, Kecamatan Abiansemal, Kabupaten Badung. 